\title{
OBSTRUCTIVE CARDIOMYOPATHY SIMULATING AORTIC STENOSIS
}

\author{
BY \\ J. F. GOODWIN, A. HOLLMAN, W. P. ClELAND, AND D. TEARE \\ From the Departments of Medicine and Surgery, Postgraduate Medical School of London, and the Department of Forensic \\ Medicine, St. George's Hospital \\ Received October 9, 1959
}

Over the past few years there has been a gradual recognition that obstruction to outflow from the left ventricle may be determined by lesions other than fusion of the aortic valve cusps or congenital diaphragms below or above the cusps. This syndrome has been described by Brock $(1957,1959)$, under the title of Functional obstruction of the left ventricle, and he instances a patient in whom hypertension produced left ventricular hypertrophy that narrowed the outflow tract of the left ventricle in systole. Bercu et al. (1958) used the term Pseudo-aortic stenosis to describe a patient with apparent aortic stenosis who at autopsy had gross generalized ventricular hypertrophy only. Morrow and Braunwald (1959), under the heading Functional aortic stenosis, instance two patients with apparent sub-aortic stenosis who at open operation were found to have no anatomical obstruction.

Recently Teare (1958), from autopsy studies, gave the first adequate description of Asymmetrical hypertrophy of the heart, a condition in which the interventricular septum in particular is grossly hypertrophied and bulges into both ventricular cavities. One of his cases presented with signs of mitral stenosis; another was studied by us during life and found to have signs of obstruction to right ventricular inflow tract, and fourteen members of her family also had heart disease with similar signs (Hollman et al., 1960). Fig. 1 shows the heart in one of these patients.

We have now seen 8 patients in whom we believe that hypertrophy of the left ventricle of undetermined cause has caused obstruction to left ventricular outflow (pseudo-aortic stenosis). Some have had signs suggesting inflow obstruction of one or both ventricles in addition, and we propose the term Obstructive cardiomyopathy as being a suitable descriptive title for the whole group. In one of our patients the obstruction was successfully dealt with by open-heart surgery.

\section{The Patients}

Case 1. A man, aged 42 years, had rheumatic fever at the age of 11 years and was told afterwards that his heart was affected. He was, however, perfectly well until the age of 36 , when he began to experience tight præcordial pain on exertion which, at the age of 40 , became worse and came on whenever he tried to hurry. Also, for 6 years he had lost consciousness on several occasions when persisting in fairly strenuous effort. Dyspnœa on effort had been minimal up to the last year when it had become more noticeable. He had a paroxysm of tachycardia at the age of 32. There was no family history of heart disease.

On examination he was a stocky man. The pulse was rather small in volume. On most occasions the upstroke was quite normal, while on others it appeared to be anacrotic. The blood pressure was 140/80 mm. The heart was quiet with a tapping apex beat and there was no thrill. A moderately loud aortic ejection murmur was heard at all areas and was louder at the apex than at the right second space. An ejection click was heard at the apex and the second sound was single. Phonocardiography showed an ejection systolic murmur of late onset and an early systolic click (Fig. 3).

The heart was of normal size but showed some fullness of the left ventricle in the lateral view on radioscopy. The aorta was normal and no valve calcification was seen. He had considerable left axis deviation (axis $-40^{\circ}$ ) with a QRS duration of 0.11 sec., absent $Q$ waves in leads V6 and $I$, and an RS pattern in V5, suggesting partial left bundle-branch block and combined ventricular hypertrophy. 


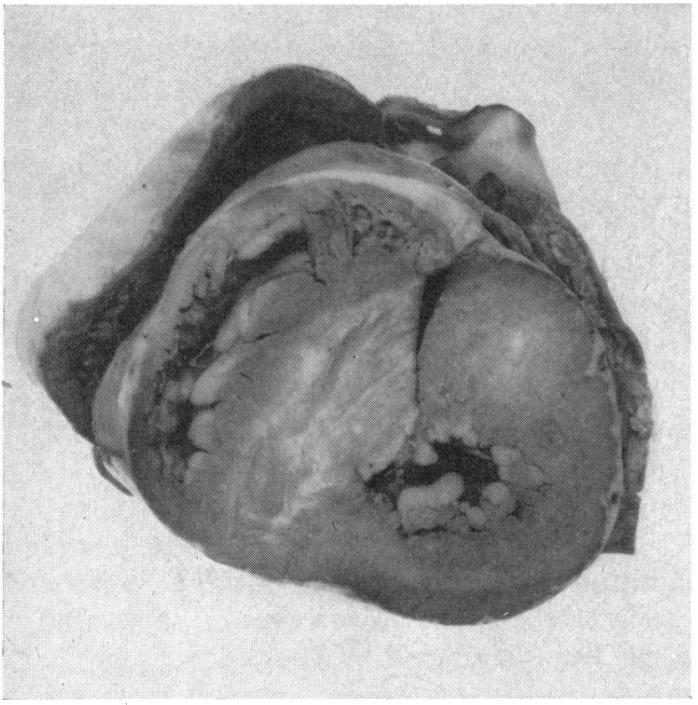

FIG. 1.-Pathological specimen of the heart of a patient with asymmetrical hypertrophy, as described by Teare (1958). The fibrosis and the asymmetry of the massive hypertrophy is well seen and the tendency for obstruction to blood flow is obvious.

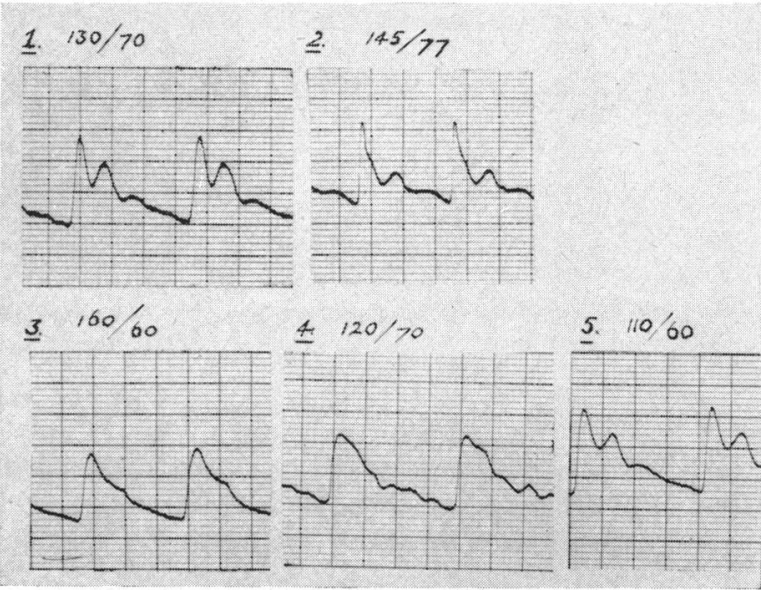

FIG. 2.-Arterial pulse tracings in Cases 1 to 5, showing abrupt upstroke and large tidal wave. Arterial pressure in $\mathrm{mm}$. Hg shown above each tracing.

An intra-arterial pulse tracing showed a delayed upstroke time of $0.26 \mathrm{sec}$. on one occasion and an abrupt upstroke of $0.07 \mathrm{sec}$. on another (Fig. 2). The Valsalva response was normal. Percutaneous puncture of the left ventricle and brachial artery showed an aortic systolic gradient of $60 \mathrm{~mm}$. $\mathrm{Hg}$, the left ventricular pressure being $155 / 18 \mathrm{~mm}$. The brachial artery pressure was $95 / 60 \mathrm{~mm}$. and the upstroke time measured $0.09 \mathrm{sec}$.

Comment. Although classical symptoms of aortic stenosis were present, we were concerned about the variable nature of the arterial pulse, the upstroke of which was sometimes rapid and sometimes delayed, the absence of valve calcification, and the systolic murmur being rather short in duration for severe aortic stenosis. We concluded that the patient probably had asymmetrical hypertrophy of the left ventricle, obstructing

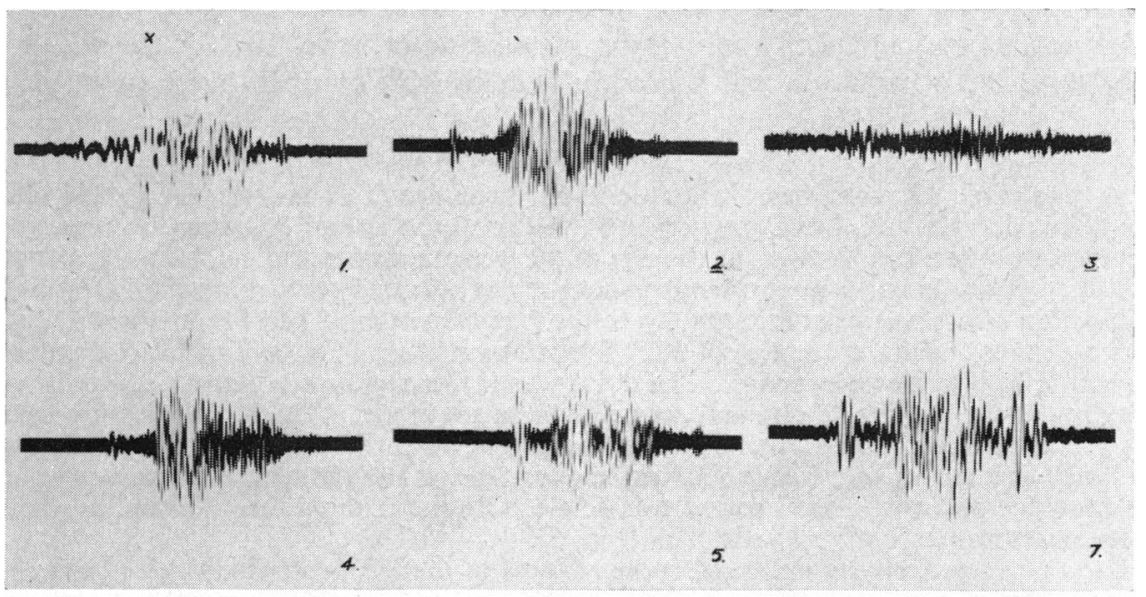

FIG. 3.-Phonocardiograms to show the ejection systolic murmur in Cases 1 to 5 and 7. $\mathrm{x}=$ systolic click. 
the outflow tract. However, we did not feel confident in excluding congenital sub-aortic stenosis, and in view of his severe symptoms decided to operate.

Operation (W.P.C.) was performed on 26/11/58. Pressure measurements showed, in mm. Hg: left ventricle 150/17, aorta 150/75, with upstroke time of $0.20 \mathrm{sec}$., and internal mammary artery $150 / 75 \mathrm{~mm}$. There was thus now no aortic valve gradient. Total cardio-pulmonary bypass was then instituted using the Melrose-N.E.P. heart-lung machine, and the heart arrested with potassium citrate. The aorta was opened and the aortic valve found to be normal. A finger was passed down into the left ventricle, and obstruction to the outflow tract, due to an enormously enlarged ventricular septum was discovered. Portions of the obstruction were excised, but a great deal of hypertrophied muscle could not be removed. The duration of cardiac arrest was 40 minutes and of bypass 55 minutes. After operation the pressures and the arterial wave form were virtually unchanged.

The post-operative course was uneventful. Follow-up for seven months has shown considerable symptomatic improvement. The patient is now able to exercise freely without angina or dyspnoea and has returned to work. The pulse is quick rising as before, but the systolic murmur is shorter and softer. The cardiogram now shows complete left bundle-branch block. In view of the small amount of muscle removed at operation the degree of improvement is remarkable.

Histological examination showed large muscle bundles arranged in a bizarre fashion (Fig. 4) and was similar to the picture in one of Teare's patients with asymmetrical hypertrophy of the left ventricle. The muscle bundles are much larger than those in a heart of similar size where left ventricular hypertrophy had been caused by hypertension.

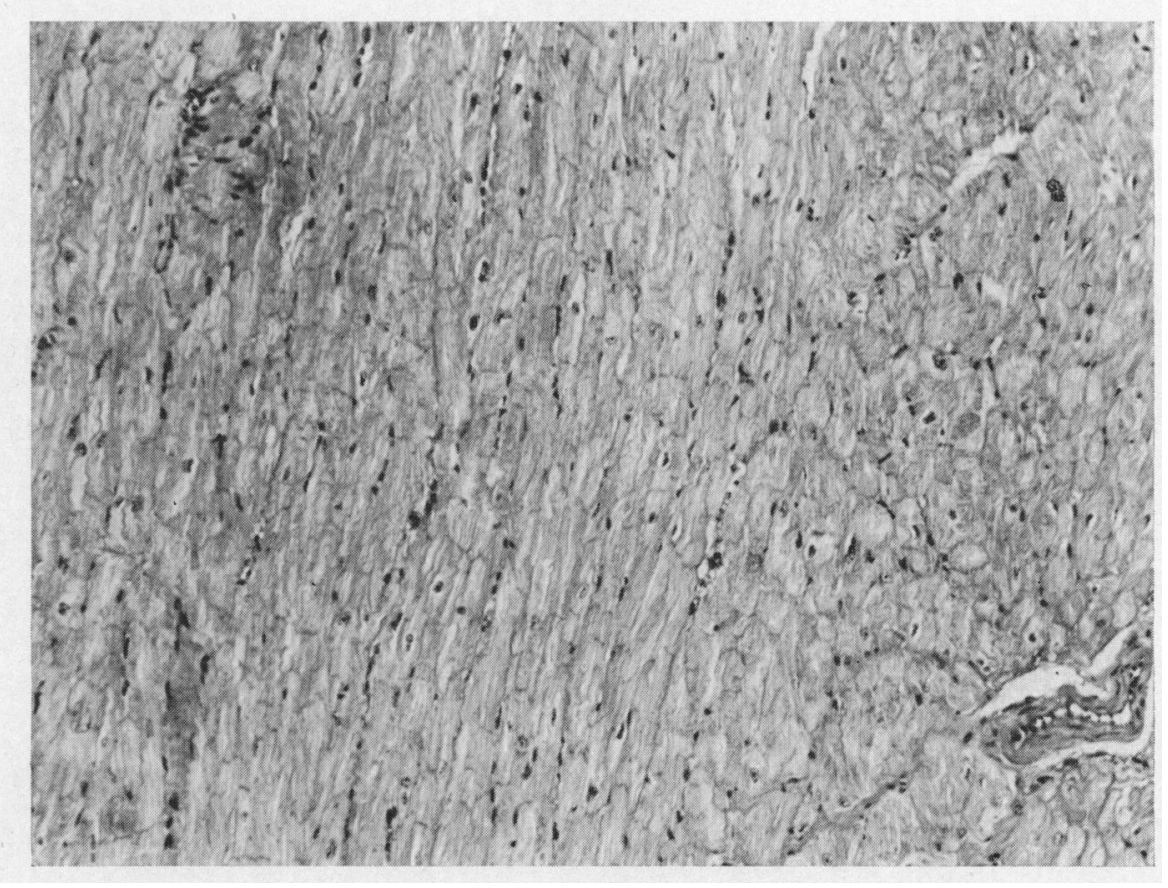

FIG. 4.-Histological appearances of ventricular muscle excised at operation (Case 1). The large muscle fibres are evident $(\mathrm{H}$ and $\mathrm{E}, \times 120)$.

Case 2. A man, aged 28, first noted dyspnœa on exertion at the age of 23 , and since 26 had found it more severe and moderately incapacitating. In addition, he had mild angina of effort: he did not complain of fatigue and had never fainted. He stated that his father suffered from heart disease.

On physical examination he looked well. The jugular venous pulse was normal and the arterial pulse was full and quick rising with a prominent dicrotic wave; it was almost bisferiens in character. The blood pressure was $100 / 55 \mathrm{~mm}$. The apex beat was strong and hyperdynamic and there was no pulsation over the right ventricle. A mid-systolic thrill was felt internal to the apex beat, but was not present at the base. An ejection systolic murmur of medium intensity was heard at all areas, loudest between the apex and the left sternal edge, and weakly conducted into the neck. A soft 4th sound was heard at the apex and the 2 nd sound was closely split. Phonocardiography showed a short ejection murmur (Fig. 3). 

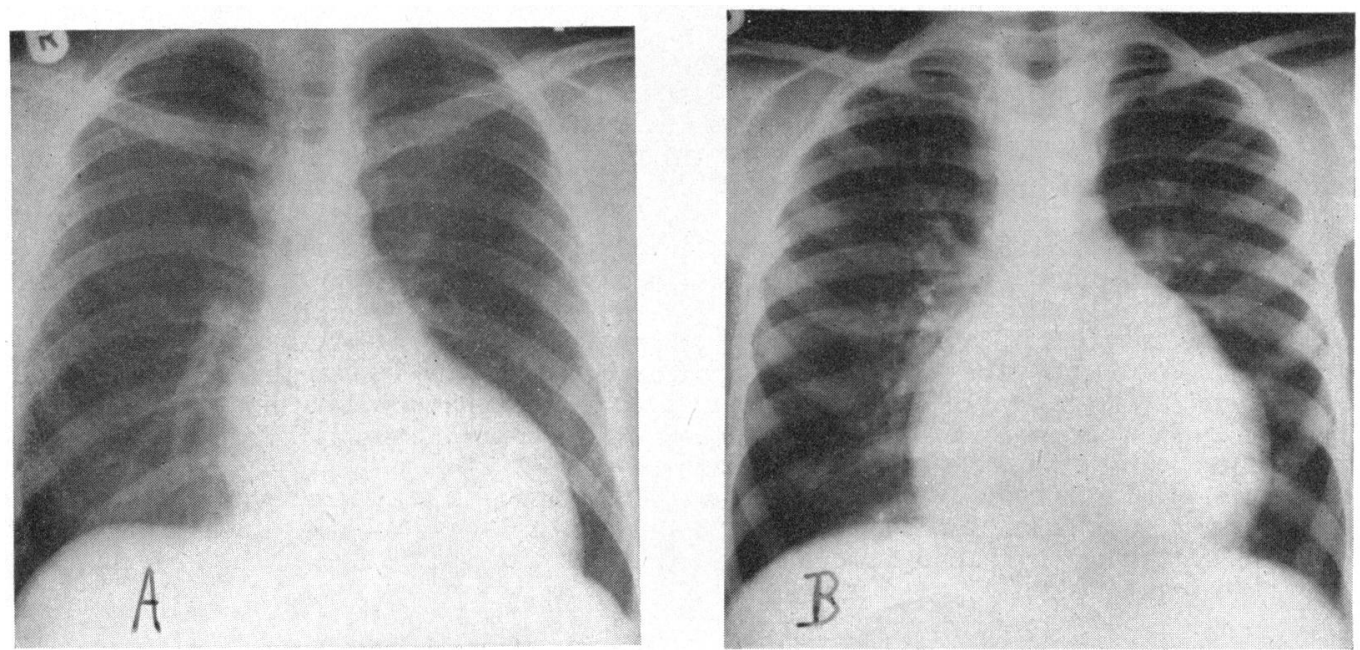

Fig. 5.-Six-foot postero-anterior radiographs. (A) Both ventricles are enlarged (cardiothoracic ratio, $58 \%$ ), Case 2. (B) Note the right and left atria (cardiothoracic ratio, $58 \%$ ), Case 6 .

Radiography showed slight dilatation of the left atrium and much enlargement of the left ventricle. The aortic valve was not calcified. The lungs appeared normal (Fig. 5).

Electrocardiography showed left axis deviation (axis $-30^{\circ}$ ) with $\mathrm{T}$ wave inversion in leads $\mathrm{I}, \mathrm{aVL}$, and V4 to V7. An rS pattern $(R / S=0 \cdot 8)$ was present in lead V5, and the $P$ wave was notched. The appearance suggested combined ventricular hypertrophy, left atrial enlargement, and possibly anterior myocardial damage (Fig. 6). An intra-arterial pulse tracing revealed a very abrupt wave front to the pulse, with an upstroke time of $0.04 \mathrm{sec}$. and a prominent dicrotic wave (Fig. 2).

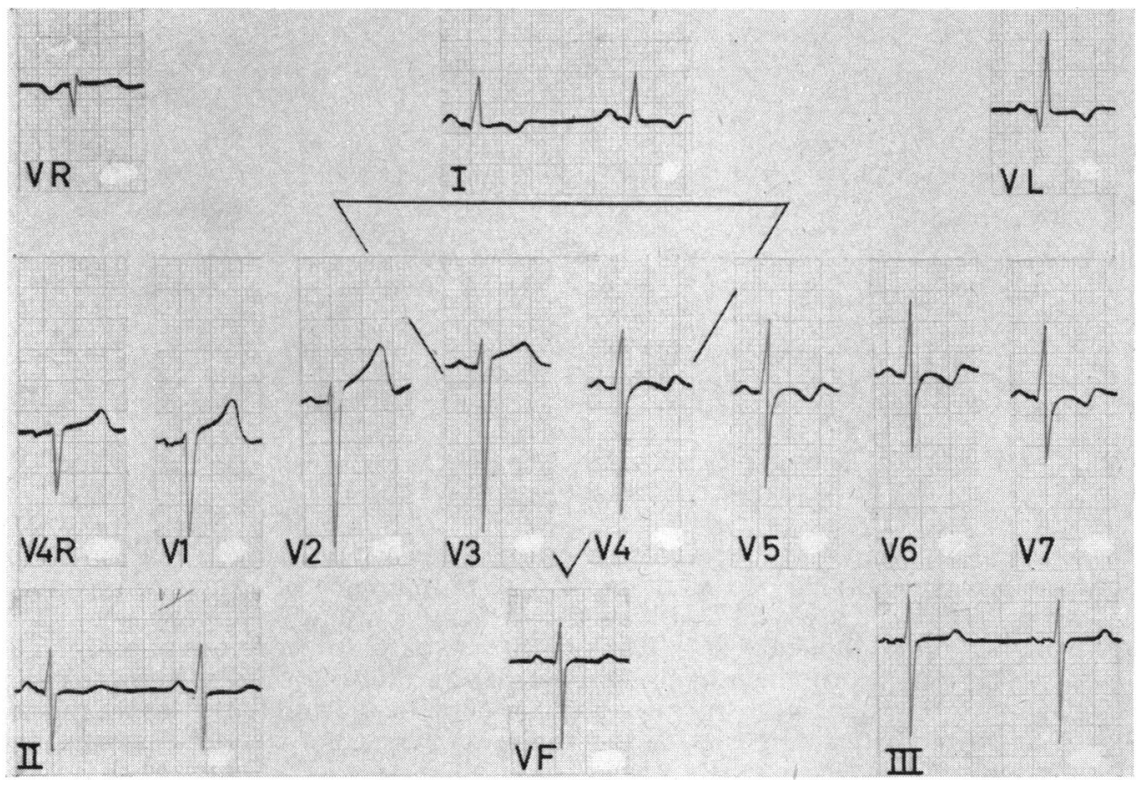

Fig. 6.-Electrocardiogram of Case 2 (see text). 
Cardiac catheterization revealed a high pulmonary capillary venous (indirect left atrial) pressure, together with a moderate degree of pulmonary hypertension. A curious and consistent finding, repeated on five occasions, was the presence of a $12 \mathrm{~mm}$. $\mathrm{Hg}$ systolic gradient low in the cavity of the right ventricle (Fig. 7). The pressures in $\mathrm{mm}$. $\mathrm{Hg}$ were as follows: right atrium, 12/6; right ventricle (low), 60/8; (high), 48/8; pulmonary artery, 48/24 (mean 35); and pulmonary capillary venous mean, 21 . The arterio-venous oxygen difference was 5 vol. per cent and the cardiac output 6.5 litres a minute. The pulmonary arteriolar resistance was 2 units. The Ry/V ratio was 2.3. Dye dilution curves were normal, excluding appreciable atrioventricular valve regurgitation or a left-to-right shunt.

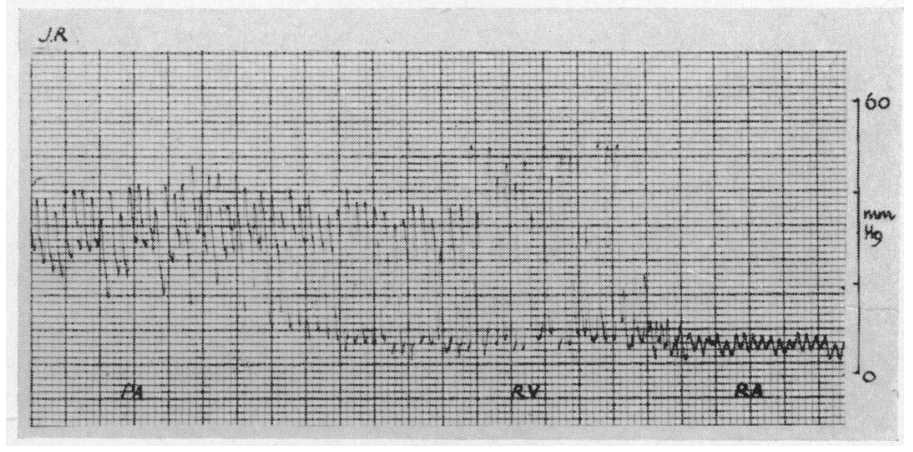

FIG. 7.-Pressure gradient in the body of the right ventricle (RV) in Case 2. $\mathrm{PA}=$ pulmonary artery. $\mathrm{RA}=$ right atrium.

Percutaneous puncture of the left ventricle and brachial artery showed an aortic systolic gradient of $65 \mathrm{~mm}$. Hg: left ventricle, 165/55; brachial artery, 100/65. In order to obtain a left ventricular pressure curve a 4-inch $(10-\mathrm{cm}$.) needle had to be thrust in up to the hilt and even then good complexes were intermittent, the systolic peak being cut off on many. The left ventricular diastolic pressure was unusually high at $55 \mathrm{~mm}$. (Fig. 8).

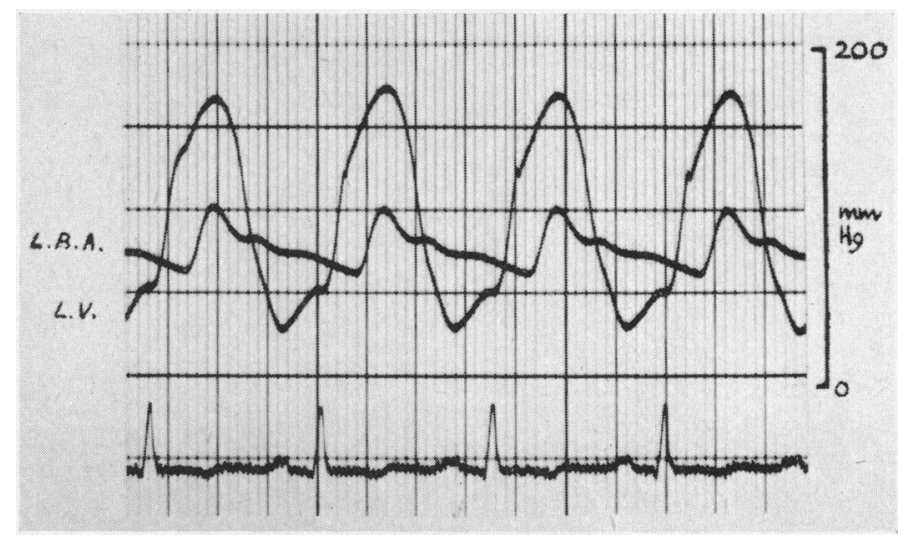

FIG. 8.-Brachial artery (LBA) and left ventricular (LV) systolic pressures in Case 2. The aortic valve gradient is $65 \mathrm{~mm}$. $\mathrm{Hg}$.

Venous angiocardiography demonstrated a distinct narrowing of the outflow pathway of the right ventricle and great hypertrophy of the left ventricle. The aortic valve area appeared normal, as did the pulmonary vessels. The left atrium was slightly enlarged and contrast medium was retained in it up to 10 seconds.

Comment. There was clear evidence of obstruction to left ventricular outflow, together with typical angina of effort. In addition, the catheterization and angiocardiographic studies showed a mild obstruction, low in the right ventricle, presumably from a hypertrophied septum. The elevated pulmonary wedge and pulmonary arterial pressures were attributed to left ventricular failure but, as suggested by Dr. 
Paul Wood who saw the patient, might have been due to hindrance to filling of the left ventricle. The features are best explained by gross hypertrophy of the left ventricle and septum, but the exact anatomical features necessarily remain speculative. The difficulty in obtaining a left ventricular pressure curve is reminiscent of the patient of Bercu et al. (1958), who was shown at autopsy to have concentric hypertrophy of both ventricles.

Case 3. A housewife, aged 49, fainted while running for a bus six months before admission. This was her first symptom, and it recurred on several subsequent occasions. One month before, she became easily fatigued and had dyspnoea on exertion, and two days before admission angina of effort was noted. There was no family history of heart disease.

On examination she was a short obese woman. The jugular venous pulse was normal and the arterial pulse was regular, full, and jerky. The blood pressure was $190 / 80 \mathrm{~mm}$. The cardiac impulses were quiet, with a soft diffuse apex beat and a slight parasternal lift. A systolic thrill was localized to the left sternal edge and an ejection systolic murmur at the same area was conducted well towards the axilla and less well to the right second space and to the neck. A 4th heart sound was present at the apex. There was some kyphoscoliosis. The second sound appeared single, but phonocardiography showed an ejection systolic murmur and narrowly split second sound (Fig. 3).

Radiography showed cardiac enlargement (cardiothoracic ratio $55 \%$ ) due to a large left ventricle, with some dilatation of the left atrium. The aorta was not dilated. No valve calcium was seen. She had complete left bundle-branch block (Fig. 10).

The intra-arterial pulse tracing confirmed a slightly rapid upstroke time of $0.09 \mathrm{sec}$. with a small dicrotic wave (Fig. 2). An indicator dye dilution curve from the right atrium was normal, excluding appreciable mitral or tricuspid regurgitation or left-to-right shunt. Venous angiocardiography showed a normal right heart and pulmonary vessels. The left ventricular wall was very thick. The aortic valve appeared normal (Fig. 9).

Comment. Typical symptoms of aortic stenosis were present but the normal pulse, the unusual location of the thrill and murmur, and the absence of visible calcium on the valve made a diagnosis of obstructive cardiomyopathy seem more likely. This view was supported by the angiocardiogram.

Case 4. A labourer, aged 29 years, was found to have heart disease 5 years before, when he had frequent respiratory infections. Since then he had noted slight dyspnoea on exertion and had twice had doubtful cardiac pain. On examination he was a strongly-built man and the venous pulse was normal. The arterial pulse was full and jerky. The blood pressure was $95 / 55 \mathrm{~mm}$. The apex beat was localized, but not very forceful, and there was no parasternal lift. At the apex there was a palpable 4th sound, a 3rd sound, and a
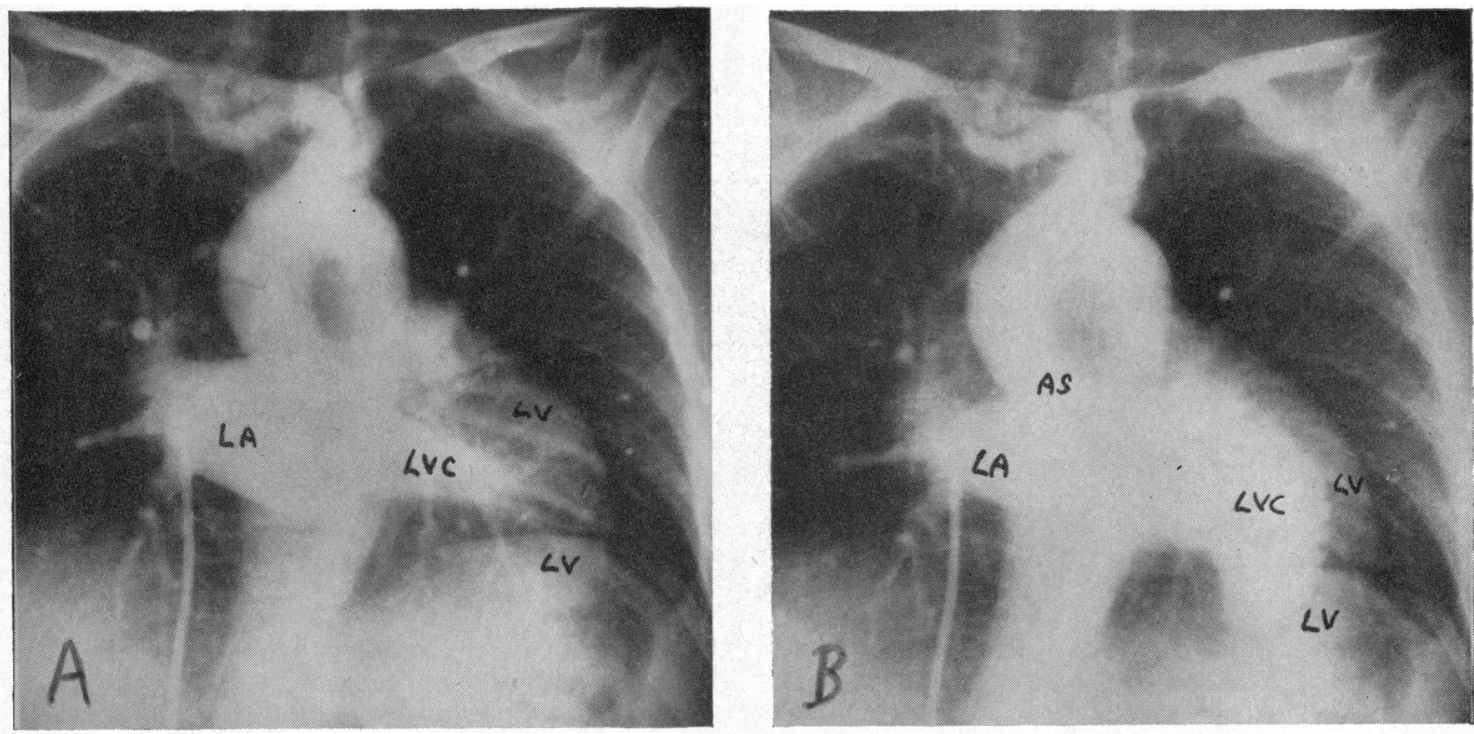

FIG. 9.-Venous angiocardiogram of Case 3. (A) In ventricular systole.' (B) In ventricular diastole. The great thickness of the ventricular muscle mass can be seen, the aortic sinuses appearing normal.

L.V. $=$ left ventricle
L.V.C. = left ventricular cavity
L.A. = left atrium

A.S. $=$ aortic sinuses. 
short mitral diastolic murmur. A long ejection systolic thrill was felt maximally medial to the apex beat and was of only moderate intensity at the base. The 2 nd heart sound showed a "reversed" split, widening on expiration. Phonocardiography showed an ejection murmur of late onset (Fig. 3).

Radiography showed moderate cardiac enlargement (cardiothoracic ratio $55 \%$ ) with some dilatation of the left atrium, and a normal aorta. There was no valvular calcification. There was $\mathrm{T}$ wave inversion in leads I, VL, and V6, with deep S waves in V2, V3, and V4. A small q wave was seen in V4 and V7, and the $r$ wave in V4 was smaller than in V4R. The $P$ wave was notched. The appearances suggested biventricular hypertrophy, small anterior myocardial necrosis, and left atrial enlargement (Fig. 10). An arterial pulse tracing revealed a rapid upstroke time $(0.08 \mathrm{sec}$.) (Fig. 2). The response to the Valsalva test was normal.

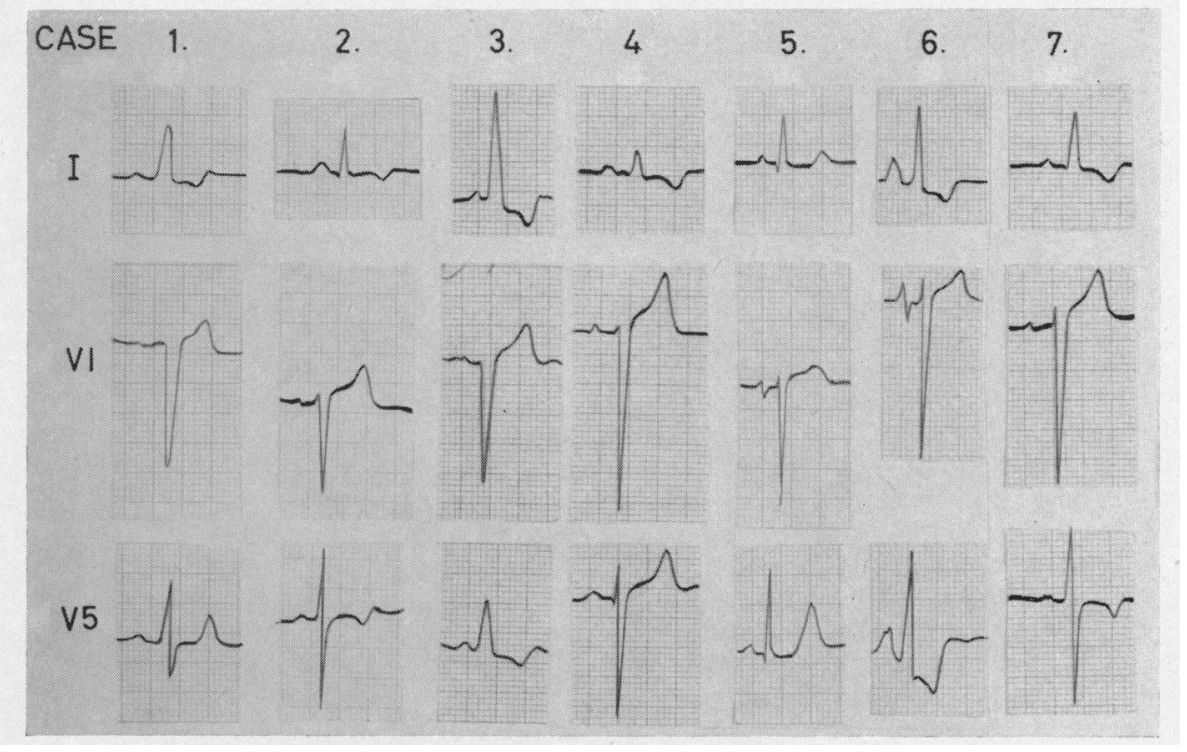

Fig. 10.-Electrocardiograms, leads I, V3, and V5, in Cases 1-7 (see text).

Comment. The combination of a long aortic systolic ejection murmur and a jerky pulse made true aortic stenosis unlikely. There was nothing to suggest pulmonary stenosis, and the unusual site of the murmur, the loud atrial sound, and the cardiographic signs suggesting hypertrophy of both ventricles suggested the diagnosis of obstructive cardiomyopathy.

Case 5. A housewife, aged 45 years, was told that she had a heart murmur during her only pregnancy 11 years before. For 3 years she had noted progressive dyspnœa on exertion and fatigue, and on one occasion had lost consciousness when running for a bus, but there had been no angina. There was no family history of heart disease. On examination she was a small woman. There was a moderately large $a$ wave in the jugular venous pulse with a somewhat sluggish $y$ descent, and the arterial pulse was of small volume with a jerky upstroke. The blood pressure was $120 / 75 \mathrm{~mm}$. The apex beat was localized but not weak, and no parasternal lift was present. A loud atrial sound was easily palpable at the apex and a fairly loud (grade 3/4) ejection systolic murmur was heard internal to the apex beat. The murmur was transmitted towards the sternum but was poorly heard at the right second space. A short mitral diastolic murmur was present. On one occasion a tricuspid diastolic murmur was noted, but was not subsequently heard. Phonocardiography showed an ejection type systolic murmur (Fig. 2).

Radiography showed that the heart was moderately enlarged (cardiothoracic ratio $60 \%$ ), the left atrium was normal, the aorta rather small, and there was no valvular calcification. The cardiogram showed a small right atrial $\mathbf{P}$ wave and normal ventricular balance with slight $S-T$ depression in V4-V7 (Fig. 10). An intraarterial pulse tracing showed a rapid upstroke $(0.08 \mathrm{sec}$.) with a prominent tidal wave (Fig. 2).

Cardiac catheterization. The pulmonary artery and pulmonary capillary venous pressures were in the high normal range and a $10 \mathrm{~mm}$. $\mathrm{Hg} a$ wave was present in the right atrium. Pressures in $\mathrm{mm}$. $\mathrm{Hg}$ were: right atrium, $a=10, x=0$, mean 7 ; right ventricle, 30/7; pulmonary artery, 30/10, mean 19; pulmonary wedge, $a=24, x=11$, mean 15 . The cardiac output was $5.51 . / \mathrm{min}$. Indicator dye dilution curves were normal, excluding appreciable mitral or tricuspid regurgitation or a left-to-right shunt.

Comment. Although there were appreciable symptoms, severe aortic valve stenosis seemed very unlikely, since the pulse upstroke was normal and no valvular calcification was found. Obstructive cardio- 
myopathy involving the inflow tracts of both ventricles, giving the large $a$ wave and the mitral diastolic murmur respectively, and involving the outflow tract of the left ventricle seemed the best explanation of the clinical picture, for the systolic murmur was ejection in type. Since it was shown by catheterization not to arise from the pulmonary artery, it presumably arose from the aorta. The evidence for right ventricular inflow tract obstruction rested upon the right atrial $\mathrm{P}$ wave on the cardiogram, the dominant $a$ wave, and the rather sluggish $y$ descent of the jugular venous pulse. The absence of a tricuspid gradient indicated that such obstruction must be slight.

Case 6. A boy, aged 7, gained weight slowly in infancy and had frequent unexplained fever up to the age of 5 years, when a heart murmur was first noted and an X-ray showed cardiac enlargement. For a few years he had become breathless when playing games and occasionally had substernal pain, especially when he had a bad cold.

On examination he was a boy of normal build and there was a giant $a$ wave in the jugular venous pulse. The arterial pulse was rather small with a quick upstroke and an easily palpable dicrotic wave, almost like a bisferiens pulse. The blood pressure was $85 / 60 \mathrm{~mm}$. The apex beat was localized and not forceful and a moderate parasternal lift was present. There was a loud ejection murmur down the left sternal edge. Loud 3rd and 4th heart sounds were heard at the apex and left sternal edge and a mid-systolic thrill was localized to the apex beat. No diastolic murmurs were heard.

Radiography showed a large heart with enlargement of all chambers, particularly the right atrium (Fig. 5B). There was much S-T depression and T wave inversion in leads $I$ and V6 and a giant notched pointed $P$ wave of $6 \mathrm{~mm}$. There was no RS pattern in V5. The appearances were consistent with left ventricular hypertrophy and right atrial enlargement (Fig. 10).

Cardiac catheterization. The intracardiac pressures in $\mathrm{mm}$. $\mathrm{Hg}$ were: right atrium, $12 / 1$; right ventricle, 70/10; and pulmonary artery, 40/23. A pressure gradient of $30 \mathrm{~mm}$. was found low in the right ventricle. There was no intracardiac shunt. Cine-angiocardiography (Dr. F. Ross) revealed some narrowing of the right ventricular outflow tract.

Comment. The picture was that of severe cardiomyopathy obstructing the outflow tract of the left ventricle and giving rise to pulmonary hypertension from left ventricular failure. The pressure gradient low in the right ventricle, the giant $a$ wave of the jugular venous pulse, and the right atrial $P$ wave could be ascribed to the greatly hypertrophied septum bulging into the cavity of the right ventricle.

Case 7. This man, aged 50, was the father of Case 2 and had no cardiac symptoms. A brother, a cousin, and a nephew of his had all died suddenly at the ages of 22,23 , and 32.

On examination he looked well and the venous pulse was normal. The arterial pulse was slightly anacrotic. The apex beat was slightly forceful and there was an easily palpable 4th sound. A loud ejection systolic murmur was best heard just inside the apex beat, and was not loud at the base. The second sound was soft. Phonocardiography showed a long ejection systolic murmur (Fig. 3).

There was moderate enlargement of the left ventricle with a normal aorta. The electrocardiogram showed an S wave in V5 and S-T depression in V7. The P wave was notched and broad. The appearances suggested biventricular hypertrophy, left atrial hypertrophy, and possibly anterior myocardial damage (Fig. 10).

Comment. The unusual features here were the apical location of the murmur, the loud 4th sound, and the strong family history. The signs were very similar to those found in his son, whose cardiogram was identical. He differed from all the other cases in having a slightly anacrotic arterial pulse. However, the inferential diagnosis of obstructive cardiomyopathy is strongly supported.

Case 8. A woman, aged 44 years, was noted to have a cardiac murmur at the age of 14 , but had no symptoms apart from occasional palpitation until 33, when the palpitation became worse and she noted faintness and dyspnœa on exertion, occasional nocturnal dyspnœa, and cardiac pain on effort. At the age of 43 she had a syncopal attack, followed by diplopia and numbness of the left side of the face. She was investigated for an intracranial vascular lesion with negative results. A brother had died of heart disease.

On examination she looked well and the jugular venous pulse was normal. The arterial pulse was jerky with a rapid upstroke. The blood pressure was $100 / 60 \mathrm{~mm}$. The cardiac impulse was diffuse, and there was a loud short ejection systolic murmur maximal down the left sternal edge, and conducted to the apex. There was a 3rd heart sound, but no thrill. The second sound seemed single. Phonocardiography showed a short loud ejection murmur of late onset. The second sound was very closely split.

Radiography showed enlargement of the left ventricle and left atrium (cardiothoracic ratio $56 \%$ ). There was no valvular calcification. There was deep $T$ wave inversion and tall $R$ waves in left præcordial leads indicating severe left ventricular hypertrophy. The $P$ waves were of left atrial type. An effort test was positive. An intra-arterial pulse tracing showed a rapid upstroke $(0.07 \mathrm{sec}$.).

Comment. The short ejection murmur, maximal at the left sternal edge and unaccompanied by a thrill, in the presence of a quick-rising arterial pulse and left ventricular preponderance on the cardiogram afforded very strong evidence for obstructive cardiomyopathy, which was further supported at this age by the absence of aortic valve calcification. 


\section{Features of The Disease}

Aetiology. Hypertrophy is not necessarily due to one single cause, but the histology in Case 1 indicates that it is not due to a tumour and has no relation to glycogen storage disorder. There is nothing to point to an infective or ischæmic cause and hypertension is not a feature, but if the condition is indeed similar to that described by Teare (1958), the evidence points towards an inherited disease, at least in some cases (Hollman et al., 1960). But in the aortic group only one patient had an affected relative as far as we could determine.

Age and Sex. The eldest patient was 50 and the youngest 7 , the average being 37 years. Five were male and three female, a higher male incidence than that found in asymmetrical hypertrophy (Teare, 1958), but the age range is very similar.

Symptomatology. The symptoms are essentially those of obstruction to cardiac output: dyspnœa, angina, and syncope. Seven of our 8 patients had dyspnœa, 6 had angina, and 4 had suffered syncopal attacks. Dyspnœa and angina were associated in 6, and dyspnœa and syncope in 2 patients. Only 3 (Cases 1, 3, and 8) had all three symptoms, while Case 7 had no symptoms at all. Not surprisingly, the symptoms are the same as those of aortic stenosis, so that differential diagnosis cannot be based upon the history. It is probable that sudden death is a risk in obstructive cardiomyopathy of aortic type, for it occurs in true aortic stenosis, and was a feature in two members of the family already mentioned (Hollman et al., 1960).

Physical Signs. We believe that obstructive cardiomyopathy can produce signs of obstruction to inflow or outflow of either ventricle, so that the signs may be expected to be protean. But in many cases the brunt falls upon one outflow tract, and when this happens to the left ventricle, true aortic stenosis is closely simulated. The association of a murmur suggesting quite severe aortic stenosis, in the presence of a normal or even quick-rising pulse, should arouse suspicion. Further differences from true aortic stenosis (Table I) are the site of maximum intensity of the murmur which may be internal to the apex, a loud 4th heart sound, absence of valvular calcification by the age of 40 years, and a family history, though this may be found with true aortic stenosis also.

Additional signs that suggest involvement of the left ventricular inflow or of the right side of the heart provide further evidence. A large $a$ wave in the jugular pulse, tricuspid diastolic murmur, enlargement of the right atrium, radiologically and cardiographically, all suggest obstruction to right ventricular inflow, while a pressure gradient low in the right ventricle on catheterization indicates obstruction in the right ventricle. When such a gradient is associated with signs of aortic stenosis, the diagnosis becomes almost certain, true pulmonary stenosis being excluded by the character of the apex beat, the pulmonary closure sound (which is not delayed or soft), the cardiogram, and the site of the gradient in the right ventricle, which is too low for infundibular stenosis.

The reason for the jerky, quick-rising pulse in the presence of left ventricular outflow obstruction is uncertain, but may be due to late contraction of the hypertrophied muscle, so that the initial portion of the maximal ejection phase of the left ventricle is rapid. This would also explain the late onset of the murmur. In Case 1 the variability of the character of the pulse would imply some alteration in the degree of obstruction from time to time. Such lability would explain the lack of aortic valve gradient at operation when previously an appreciable gradient had been measured.

The Radiological Appearances. There is little specific about the cardiac silhouette in most cases, though prominence of the right atrium favours tricuspid obstruction and may be striking (Fig. 5B). Enlargement of the left atrium may occur, while left ventricular enlargement is very common. The really important sign is a negative one, the absence of calcification of the aortic valve in patients over the age of 40 years: this virtually excludes valvular aortic stenosis, though not of course congenital sub-aortic stenosis.

The Electrocardiogram. The major features are signs of left ventricular hypertrophy with a deep $S$ wave in lead V5 suggests that additional right ventricular hypertrophy. Signs of atrial enlargement are common, and the association of signs of much left ventricular hypertrophy with a striking right atrial $P$ wave (which is uncommon in true aortic stenosis) is highly suggestive (Case 6, Fig. 10). $\mathrm{T}$-wave inversion in central chest leads may be due to right ventricular enlargement, but in two of 
our cases there were $q$ waves suggestive of muscle necrosis in the septal region. This feature would accord well with the presence of massive septal hypertrophy and fibrosis, as would left bundlebranch block which was present in two of our cases. We do not consider that the cardiogram alone is sufficiently typical or consistent as to be diagnostic, but the association of the features mentioned with the clinical picture affords valuable help in diagnosis.

\section{Discussion}

In our first patient it is likely that the subvalvular obstruction was due to asymmetrical hypertrophy of the left ventricle, but the cases published by Brock (1957) and by Bercu et al. (1958) show that such obstruction may be produced equally well by concentric hypertrophy. Furthermore, these authors showed that the hypertrophy might be familial or secondary to essential hypertension. It is thus clear that this syndrome of pseudo-aortic stenosis is likely to be associated with more than one cause of left ventricular hypertrophy and that the anatomical features too may be varied. In Bercu's patient both ventricles were greatly hypertrophied and the ventricular cavities represented by "mere uniform slits throughout their entire length": they had found it impossible at thoracotomy

TABLE I

Features of True Aortic Stenosis and Obstructive Cardiomyopathy

\begin{tabular}{|c|c|c|}
\hline Feature & Obstructive cardiomyopathy & True (valvular) aortic stenosis \\
\hline Family history & May be familial & 一 \\
\hline Symptoms & Dyspnœa, angina, syncope & Dyspncea, angina, syncope \\
\hline Arterial pulse & $\begin{array}{l}\text { Quick upstroke, jerky. Prominent } \\
\text { tidal wave }\end{array}$ & Anacrotic \\
\hline Cardiac impulse & May be quiet and diffuse & Strong left ventricle \\
\hline Systolic ejection murmur & Maximal internal to apex beat & Maximal at aortic area (or apex) \\
\hline Reversed split of 2 nd heart sound & Rare & Common \\
\hline Systolic click & Occasional & Not infrequent \\
\hline Aortic diastolic murmur & Not found & Not uncommon \\
\hline Mitral diastolic murmur & Not uncommon & Not uncommon \\
\hline $\begin{array}{l}\text { Prominent } a \text { wave in jugular venous } \\
\text { pulse }\end{array}$ & May be striking & $\begin{array}{c}\text { Unimpressive unless pulmonary } \\
\text { hypertension }\end{array}$ \\
\hline Atrial sound & Common & Unusual \\
\hline Right atrial $P$ wave in EC & Common & Rare \\
\hline Prominent $\mathrm{S}$ wave in lead V5 in EC & Frequent & Less common \\
\hline $\begin{array}{l}\text { Central præcordial } \mathrm{T} \text { wave inversion } \\
\text { in } \mathrm{EC}\end{array}$ & Common & Less common \\
\hline Aortic valve calcification & Never seen & Common; invariable after age of 40 \\
\hline Enlargement of right atrium & Common & Unusual \\
\hline Right heart catheterization & $\begin{array}{l}\text { Pressure gradient in body of right } \\
\text { ventricle }\end{array}$ & No gradient \\
\hline Left heart catheterization & $\begin{array}{l}\text { Gradient across left ventricular } \\
\text { outflow tract may be variable }\end{array}$ & $\begin{array}{l}\text { Gradient constant across aortic } \\
\text { valve }\end{array}$ \\
\hline
\end{tabular}


to obtain a pressure tracing with a needle thrust into the left ventricle. In Brock's patient, autopsy showed "gross concentric hypertrophy extending right up to the subvalvar region": the cavity of the ventricle, however, was large enough to permit an expanding dilator to be opened freely in the outflow tract at operation. Whether it would have been possible to help these patients by resection of the sub-valvular region is impossible to say, since it was not done, but at least in Bercu's patient this seems very unlikely. However, our own patient (Case 1) who was operated on has done so well that it seems possible that in some patients this syndrome may be operable.

But many patients with pseudo-aortic stenosis may be inoperable for one reason or another, even with open-heart surgery, and the problem of diagnosing them from patients with operable lesions is an important one. Table I shows the main distinguishing features. Undoubtedly, the normal upstroke time of the arterial pulse, and over the age of 40 the absence of aortic valve calcification, are two of the most important differential points. In all our patients, and in Bercu's also, the systolic thrill and murmur were appreciated best internal to the apex, not at the base, and we find this a very helpful point. This distribution of the murmur has given rise to confusion with mitral regurgitation and occasionally with ventricular septal defect. In those patients with evidence of obstruction to right ventricular inflow, such as an augmented $a$ wave in the venous pulse, right atrial $\mathbf{P}$ wave on the cardiogram, and a large right atrium on X-ray, the distinction from true aortic stenosis has been even more clear. We have observed (Hollman et al., 1960) such signs in several members of the family of whom two died suddenly and were found at autopsy to have asymmetrical hypertrophy of the left ventricle (Teare, 1958). The pressure gradient, low in the right ventricle in two of the patients in the present series, we ascribe also to the hypertrophied septum.

Awareness of the condition is essential, for diagnosis principally depends upon the association of the clinical signs already mentioned, supported by radiological, electrocardiographic, and phonocardiographic studies. The most helpful additional investigation is right heart catheterization, which may reveal a gradient in the body of the right ventricle.

Probably the most difficult aspect in differential diagnosis will be to separate these cases from the occasional patient with a sub-aortic diaphragm in whom the arterial pulse is normal. This latter combination is known to occur ( $\mathrm{P}$. Fleming, personal communication). A really clear delineation of the outflow tract of the left ventricle is possible by means of an angiocardiogram performed via percutaneous puncture of the left ventricle (Björk et al., 1958), and this may prove to be the method of choice, for venous angiography may fail to show the left ventricle sufficiently well. However, the great improvement achieved in our Case 1 by operation may make this differentiation somewhat academic, although on the other hand two patients operated on by Morrow and Braunwald (1959) did not have any muscular obstruction that could be removed. In the present state of our knowledge, we would be reluctant to advise operation in the presence of evidence of obstruction to the right side of the heart also.

The term functional aortic stenosis has been used both by Brock $(1957,1959)$ and by Morrow and Braunwald (1959) and deserves some comment. Their reasons for this designation lay in the fact that the outflow tract of the left ventricle was not appreciably narrowed anatomically, as shown at operation by the ready passage of instruments or the finger through it. They visualized the outflow tract becoming greatly narrowed in systole only. However, this could not occur without some hypertrophy of the ventricle (which was present in their patients) and so did constitute a real anatomical lesion, even if less than they expected. Moreover, in our Case 1 the anatomical obstruction was quite obvious. We think, therefore, that the term functional is somewhat misleading and would be better abandoned.

\section{SUMMARY}

The term obstructive cardiomyopathy is proposed to describe a condition of massive ventricular hypertrophy that obstructs the outflow pathway of the left ventricle and mimics aortic stenosis. The disorder may also produce obstruction to right ventricular outflow or inflow. The aetiology, clinical features, results of special investigations, and treatment are discussed with special reference to the differential diagnosis from true aortic stenosis. 


\section{ADDENDUM}

Since preparing this paper, two additional and similar cases masquerading as aortic stenosis have been reported by Soulié et al. (1959); one of them came to necropsy and showed gross hypertrophy of the septum.

Since this paper was written V. O. Björk (personal communication) has told us of two patients in whom subaortic stenosis was produced by an abnormally placed anterior mitral leaflet. The physical signs were similar to those in our own cases in that the bruit was loudest near the apex and the pulse had a normal upstroke. The abnormal leaflet was clearly seen in left ventricular angiocardiograms, which also showed slight mitral regurgitation, and its presence was confirmed at operation in both cases. entity.

This illustrates our point that aortic stenosis may be simulated by more than one pathological

We are very grateful to Professor A. V. Neal and Dr. D. H. Davies who kindly referred Case 6; to Dr. F. Ross for allowing us to see the cine-angiocardiogram; and to Dr. D. Lewes, who referred Case 1.

\section{REFERENCES}

Bercu, B. A., Diettert, G. A., Danforth, W. H., Pund, E. E., Jr., Ahlvin, R. C., and Belliveau, R. R. (1958). Amer. J. Med., 25, 814.

Björk, V. O., Jonsson, B., and Nordenström, B. (1958). Thorax, 13, 201.

Brock, R. C. (1957). Guy's Hosp. Rep., 106, 221. (1959). Guy's Hosp. Rep., 126, 108.

Hollman, A., Goodwin, J. F., Teare, D., and Renwick, J. W. (1960). Brit. Heart J., 22, 449.

Morrow, A. G., and Braunwald, E. (1959). Circulation, 20, 181.

Soulié, P., Degeorges, M., Joly, F., Caramanian, M. and Carlotti, J. (1959). Arch. Mal. Caur, 52, 1002.

Teare, D. (1958). Brit. Heart J., 20, 1. 